\title{
LA OTRA ESCRITURA DE PABLO NERUDA, LOS EPISTOLARIOS
}

\author{
Abraham Quezada Vergara ${ }^{1}$ \\ asquezada@gmail.com \\ "Son las 11 de la mañana en Normandia, \\ y a esta hora me toca escribirme cartas a mi mismo, que los otros llaman poemas"
}

(Pablo Neruda, marzo de 1972)

Se acaba de cumplir el primer centenario de la epistolografía nerudiana. Precisamente hace un siglo, el 30 de junio de 1915, el entonces niño Neftalí, que estaba por cumplir los once años de edad, le escribió a su "mamadre" una especie de saludo semi-rimado en una tarjeta postal en donde le decía: "De un paisaje de áureas regiones yo escogí para darle querida mamá esta humilde postal". A partir de este primer registro documentado de actividad epistolar en el poeta, aún no famoso, y tras casi siete décadas de una vida intensa y singular, se conformó un formidable entramado de intercambios en donde el autor de los 20 Poemas de amor y una canción desesperada dio rienda suelta a sus inquietudes y necesidades, informando de sus deseos y aspiraciones literarias, laborales y amorosas, de sus furias y de sus penas y de su apasionamiento político e intelectual. En esos textos entregó su opinión y parecer acerca de una infinidad de hechos, asuntos y circunstancias. Todo lo cual ha terminado por conformar el "revés de la trama" (Greene 2001), y no solo de su vasta y original obra literaria, sino también de su existencia vital.

Al volcar en una tinta epistolar su discurso privado se pueden seguir las trazas y las secuencias de una realidad transida de circunstancias de todo orden, desde las menudas y cotidianas, pasando por las personales y familiares, hasta aquellas de índole pública, sin dejar de lado asperezas, incomprensiones y cuestionamientos. En definitiva, a través de su epistolario podemos acceder al develamiento del tesoro de una intimidad en toda su plenitud e integridad. Así, al cumplirse una centuria del inicio de esta "otra escritura", resulta oportuno ponderar esta "nueva frontera" en los estudios nerudianos y reflexionar acerca de su importancia. 


\section{EL DISCURSO EPISTOLAR DEL POETA}

La obra canónica de Neruda alcanza casi una cincuentena de libros, en cambio su obra dispers $a^{2}$ y producto de la profusa e intensa actividad intelectual, social y política que desarrolló por décadas, se presenta abultada y, a la fecha, no determinada ni catalogada del todo ni recogida en un corpus único. Pese a los esfuerzos de investigadores y estudiosos, esta suerte de itinerario paralelo yace disperso en bibliotecas, en colecciones privadas o en repositorios documentales tanto dentro como fuera de Chile. En su conjunto posee un valor más documental que literario, y por lo mismo, deviene en indispensable para completar y complementar, "por su propia mano", la biografía descrita parcialmente en libros como Confieso que he vivido.

Los epistolarios, asumidos como un componente fundamental de la obra dispersa, si bien son concebidos como un género discursivo referencial y no ficcional ${ }^{3}$, pueden considerarse la forma más pura de la autobiografía, por lo mismo, un escritor, un poeta, un intelectual, es la totalidad de su lenguaje. A partir de estos supuestos, en el quehacer privado y público de un autor, la carta adquiere una importancia excepcional, que una vez develada ayuda a la compresión cabal del sujeto histórico. Se trata entonces de asumir cómo un espacio esencialmente íntimo y privado, gestado en el transcurso de una vida y, aunque el mismo poeta haya señalado con cierta preocupación el hecho que "un día publicarán hasta mis calcetines" (Varas 2004), reclama presencia pública con el propósito ya enunciado.

Desde sus años juveniles y hasta poco antes de fallecer, Neruda fue un escritor que se valió del género epistolar de forma desbordante. "Poeta epistolero" lo llamó su amigo Volodia Teitelboim (Quezada 2004: 17). El vate utilizó este medio para expresar su amor y urgencias, otras veces para dar a conocer sus versos y conectar a sus amigos y familiares. No faltan aquellas cartas que expresan su opinión o desagrado acerca de la contingencia. Características que se verán acrecentadas al sumar lejanías, producto de su trabajo consular y diplomático, y por sus posteriores y constantes viajes al extranjero. A través de esta vía, en definitiva, se mantuvo en contacto con Chile y el mundo, conquistando progresivamente sus ansiados objetivos literarios y de otro orden.

Así, la carta nerudiana se presenta como una práctica discursiva, aun cuando no se la considere como un texto propiamente literario, pues aunque sea de un modo independiente, está íntimamente relacionada con el deseo de escritura y es parte de una evidente pulsión autobiográfica. Su revisión cuidadosa ayuda a reconstruir momentos y detalles de la personalidad del remitente y los pormenores de su acontecer. Entonces, más

2 Compuesta de cientos de declaraciones, entrevistas, discursos, intervenciones políticas variadas, recados, notas, dedicatorias y cartas, tanto públicas como privadas. Las Obras completas de Pablo Neruda editadas por Hernán Loyola (Galaxia Gutenberg - Círculo de Lectores, 1999 -2002) de los cinco volúmenes considerados, dos están dedicados a la llamada Nerudiana Dispersa.

O también llamados géneros menores o no-canónicos. 
allá de los discursos y del imaginario poético-literario del corresponsal, la lectura atenta y comprensiva de sus epistolarios permite acceder a "esferas específicas de identidad personal", las que junto con iluminar y ayudar a entender el proceso creador de su autor, facilitan enormemente el ansiado "despliegue del autorretrato" (Boersner 2000: 4), fin último de la investigación histórico-literaria.

\section{ALGUNOS DESAFÍOS DEL DISCURSO EPISTOLAR}

Hurgar en una correspondencia privada, considerada la mayoría de las veces como un mero instrumento comunicativo, supone ciertos desafíos y riesgos. Más allá de lo valioso que resulta como documento histórico y lo interesante que puede ser develar o conocer escritos que provienen de alguien cuyo oficio es -precisamente- la literatura, la carta privada conlleva un potencial contra-discursivo frente al canon hegemónico mayor. Es decir, expone al escrutinio de los otros la coherencia entre lo que se dice y lo que se hace. Por otra parte, al redactar una carta, el sujeto se modifica en su aproximación al otro, y por esto en cada correspondencia podría elaborar a un sujeto particular, determinado por el tipo de relación que establece. Así, al examinar una correspondencia con distintos destinatarios, como ocurre en el caso nerudiano, podría ser factible enfrentarse a más de un personaje, o bien a un personaje múltiple. Por último, este género, y especialmente cuando se trata de cartas privadas, mantiene su carácter permanentemente ambiguo y fronterizo entre la ficción y la realidad, entre lo público y lo privado y entre lo considerado literario y lo no literario.

\section{EVOLUCIÓN DE UN EPISTOLARIO}

Estos estudios fueron inaugurados con gran entusiasmo y dedicación por Margarita Aguirre a comienzo de los años sesenta, cuando al preparar su biografía sobre "su compadre", advirtió los pocos testimonios que existían de la etapa de su estada en Oriente y del proceso creador del libro Residencia en la tierra. En esa ocasión, Neruda le insinuó que en esa época había mantenido un activo contacto epistolar con un escritor argentino de apellido Eandi.

Al conocer e interiorizarse de ese intercambio, Margarita de inmediato sopesó su importancia señalándole: El epistolario es fantástico. Creo que no se podrá hacer un estudio serio sobre la obra de Pablo sin tenerlo en cuenta. Pienso copiarlo todo a máquina, mandarles una copia para ustedes y Sanhueza y creo que sería interesante publicarlo con notas o un estudio de la época. Yo he estado tan feliz con este descubrimiento del epistolario que no hablé de otra cosa en varios días ${ }^{4}$. Rápidamente, Neruda le

$4 \quad$ Carta de Margarita Aguirre a Pablo Neruda, Buenos Aires, 13 de octubre de 1962. En Archivo Fundación Pablo Neruda, sección correspondencia. 
respondió: Me sorprendieron las cartas para Eandi. Cuántas personas somos, hemos sido! En cuanto a las cartas epistolares creo que se pueden publicar. Hay que hacerles ligerísimas supresiones. Pueden editarlas aqui Universitaria, si quieres. Me parece que Eandi debiera prologarlas y tú introducirlas. Yo no opino sobre ellas ${ }^{5}$. Años más tarde, Margarita volvió a la carga: yo quiero insistir (a riesgo de ser cargosa) en las cartas de Eandi... yo le atribuyo igual importancia ${ }^{6}$. Así, la contribución de su "comadre" es incuestionable en valorar y difundir este ámbito del quehacer nerudiano como una fuente relevante para el estudio y conocimiento de su vida y obra.

Luego de la muerte del poeta, en 1973, se editaron los epistolarios "fundacionales", como Cartas de amor de Sergio Fernández Larrain (1975), Cartas a Laura de Hugo Montes (1978) y Correspondencia durante "Residencia en la Tierra" de Margarita Aguirre (1980) ${ }^{7}$. Otros trabajos de esta naturaleza aparecieron como artículos, como el de Vera Kutéischikova de 1976, titulado las "Cartas del poeta, Correspondencia entre Volodia Teitelboim y Pablo Neruda”. Más tarde, en 1984, Inés María Cardone publicó "Las cartas personales entre Pablo y Gabriela". Ciro Bianchi Ross en 1991 publicó en La Habana "Neruda inédito", que contenía el intercambio mantenido con Juan Marinello. Más tarde, en el 2004, Francisco Caudet publicó las cartas que Neruda intercambió con la Agencia Literaria ALA. Otros trabajos similares ${ }^{8}$ han sido el de Arely Mendoza de León en Olor a caoba. El aroma de Guatemala, en el 2004, que incluyó la correspondencia

5 Carta de Pablo Neruda a Margarita Aguirre [Isla Negra], 20 de noviembre de 1962. En Archivo Fundación Pablo Neruda, sección correspondencia.

6 Carta de Margarita Aguirre a Pablo Neruda, Buenos Aires, 11 de diciembre de 1967. En Archivo Fundación Pablo Neruda, sección correspondencia.

7 En el 2008 Edmundo Olivares reeditó dicho epistolario bajo el título Itinerario de una amistad. Pablo Neruda Héctor Eandi. Buenos Aires: Ediciones Corregidor.

8 Algunos de los trabajos que no siendo epistolarios o correspondencias selectas han incluido cartas valiosas son: Alone, Los Cuatro grandes de la literatura chilena, Augusto D'Halmar, Pedro Prado, Gabriela Mistral y Pablo Neruda (1962); Emir Rodríguez, Neruda, El viajero inmóvil (1985); José Miguel Varas, Aquellos anchos días Neruda el oriental (1991); Hernán Soto, Tomás Lago, Ojos y oídos cerca de Neruda (1999); Hernán Loyola, Pablo Neruda Obras Completas. 5 vols. (1999-2002); Bernardo Reyes, Neruda Retrato de Familia 19041920 (2003); David Schidlowsky, Las Furias y las penas. Pablo Neruda y su tiempo (2003); Volodia Teitelboim, Neruda, la biografia (2003) y César Soto y Sara Vial quienes editaron en el 2004 El libro de los libros de Pablo Neruda y Neruda vuelve a Valparaíso, respectivamente, y Neruda. El Príncipe de los poetas, de Mario Amorós (Ediciones B, 2015). En otros idiomas, como en italiano, en el 2005 Maurizio Nocera editó las cartas que el vate intercambió con Alberto y Bianca Tallone y la Revista "Nerudiana" en el 2012, incluyó la correspondencia que Neruda mantuvo con Piero Fornasseti. Recientemente, Gabriele Morelli editó en español algunos epistolarios nerudianos bajo el título Cartas de amor (Cátedra 2015.) Por su dispersión no se incluyen en este somero recuento una gran cantidad de textos epistolares del poeta que se encuentran publicados en medios de prensa, artículos y/o en revistas especializadas de carácter académico. 
del chileno con Luis Cardoza y Aragón y Enrique Muñoz Meany y Cartas de Amor de Neruda con Matilde Urrutia, al cuidado de Darío Oses, en 2010. Por mi parte, desde el 2004 en adelante he publicado la correspondencia consular y diplomática del poeta, así como los intercambios mantenidos con Jorge Edwards, Gabriela Mistral, Tom Maschler (inédito) y Claudio Véliz, entre otros.

\section{LOS TEMAS PREDOMINANTES DE UNA TRAYECTORIA EPISTOLAR}

Desde sus tempranos años juveniles y hasta comienzo de los años setenta, el universo epistolar nerudiano produjo varios cientos de lotes y cartas sueltas dirigidas a interlocutores múltiples y siempre conteniendo una gran profusión temática. Aunque se trata de un material abultado, esencialmente inédito y disperso, es posible, y de manera tentativa, proponer una distinción básica. Por una parte están las cartas de carácter público y por otra, en su gran mayoría, las de naturaleza privada. En estas últimas, predominan las de tipo familiar, las fraternales y las amorosas, cuya redacción suele ser breve, original, juguetona y hasta graciosa, además de honestas, abiertas y cálidas. En ocasiones se presentan vivaces y concretas, pero siempre de una gran eficacia expresiva y sin artificios retóricos. Junto con acentuar la nostalgia a través de detalles domésticos, prosaicos, su disposición se presenta desenvuelta, familiar y amena, manteniendo una tendencia hacia lo pintoresco y anecdótico. Es, en general, una prosa epistolar intuitiva, descriptiva, rica en matices y giros y con momentos de gran viveza y alegría. 
240

Revista Chilena de Literatura No 93, 2016

Mafo 91964

ouends, cuantit timps sin veres, Clandiv, Paula! Veraín que en higota. As que urs mandaro preiden le nueva taberin de 1. Nelpe.

Tambor - Eldr onequ Hotel pulma está en Pas ovolvera' ho bases 4 Boule rand Taber el me traerí Raspail el drum. Pero potrié pain liajoir haste 20 peerto para entarcarse? quies preguntísel? thas hatuegr, salioun en munator en gerie de 10 drás in Allend, pr Bi-Bio ? Aranco Sanaveurs

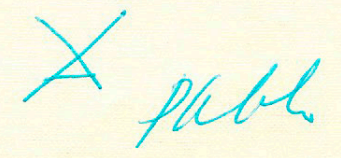

Carta de 9 de mayo de 1964: incluida en Quezada, Abraham (2011) Pablo Neruda-Claudio Véliz, Correspondencia en el camino al Premio Nobel, 1963-1970. Santiago: Ediciones de la Dirección de Bibliotecas, Archivos y Museos, página 73. 
En el plano íntimo, la correspondencia nerudiana irrumpe, arrasa e invade y se presenta libre, segura y dueña de su albedrío. Asimismo, conlleva una marcada "impronta instrumental" (Quezada 2011: 22), es decir, que las cartas son funcionales a los apetitos del poeta, como a su afán coleccionista o intelectual. En sus textos se siente soberano para improvisar su pensamiento y sentimientos y también se disciplina al estrenar ideas delante de interlocutores intelectualmente exigentes. Como tendencia general, llama la atención que en ese torrente informativo-inquisitivo de novedades y necesidades y sin dejar de lado expresiones de cariño y afecto, no incorpore comentarios dolorosos acerca de situaciones vividas, ni siquiera sus a veces penosas peregrinaciones de expatriado. El enfado e irritación que le provocó la cuestionadora carta de los intelectuales cubanos de agosto de 1966 o el mortífero cáncer que a comienzos de los años setenta lo carcomía y le arrebataba la vida, no ocuparon espacio epistolar ni tampoco el desgano o el abatimiento. Por el contrario, la presencia de frases cálidas y el deseo de emprender siempre nuevos proyectos de trabajo y convites de alegría, se mantuvieron inalterados, lo que prueba que el poeta hasta el final de sus días sostuvo una valiente lucha para sobreponerse a las dificultades.

Las misivas públicas de Neruda, en cambio, son de orientación principalmente cívica y ciudadana, y dan muestra de una permanente defensa y toma de posición enmarcada en la visión de su tienda política en medio de las complejidades de la Guerra Fría. La defensa de ideas y planteamientos de su sector es irrestricta y comprometida. Por lo mismo, sus afirmaciones políticas suelen estar acompañadas de cierto maniqueísmo y de una fuerte dosis de voluntarismo.

En su conjunto, el estilo epistolar nerudiano seduce de inmediato con datos implícitos que iluminan la importancia que éste y su entorno le concedían a un sinfín de aspectos y situaciones, articulando variadas e inesperadas claves de lectura y comprensión no consideradas en las biografias hasta ahora publicadas. En ambos tipos de cartas lo testimoniado suele ir conexo a la realidad cotidiana. También llama la atención que, dejando de lado su formación e intereses literarios o políticos, regularmente aflore el uso de la llamada jerga chilena y/o jerga familiar. Otra singularidad es que las consideraciones del poeta suelen estar teñidas de lo que se podría llamar "chilecentrismo", intercalando palabras y frases en otros idiomas, principalmente inglés y francés. Más que cometer faltas de ortografía, el poeta persiste en hacer "muecas a la gramática"; como poner en altas los nombres de los meses, eliminar los signos abre-exclamación y abre-interrogativos, escaso o nulo uso del punto y coma y el cambio de orden de las letras iniciales de algunas palabras ${ }^{9}$.

9 A fines de los años sesenta le confirmará a su amiga Margarita Aguirre que las reglas ortográficas las había suprimido "hace 45 años". En Carta de Pablo Neruda a Margarita Aguirre [Isla Negra,] 4 de marzo de 1969. En Archivo Fundación Pablo Neruda, sección correspondencia. 


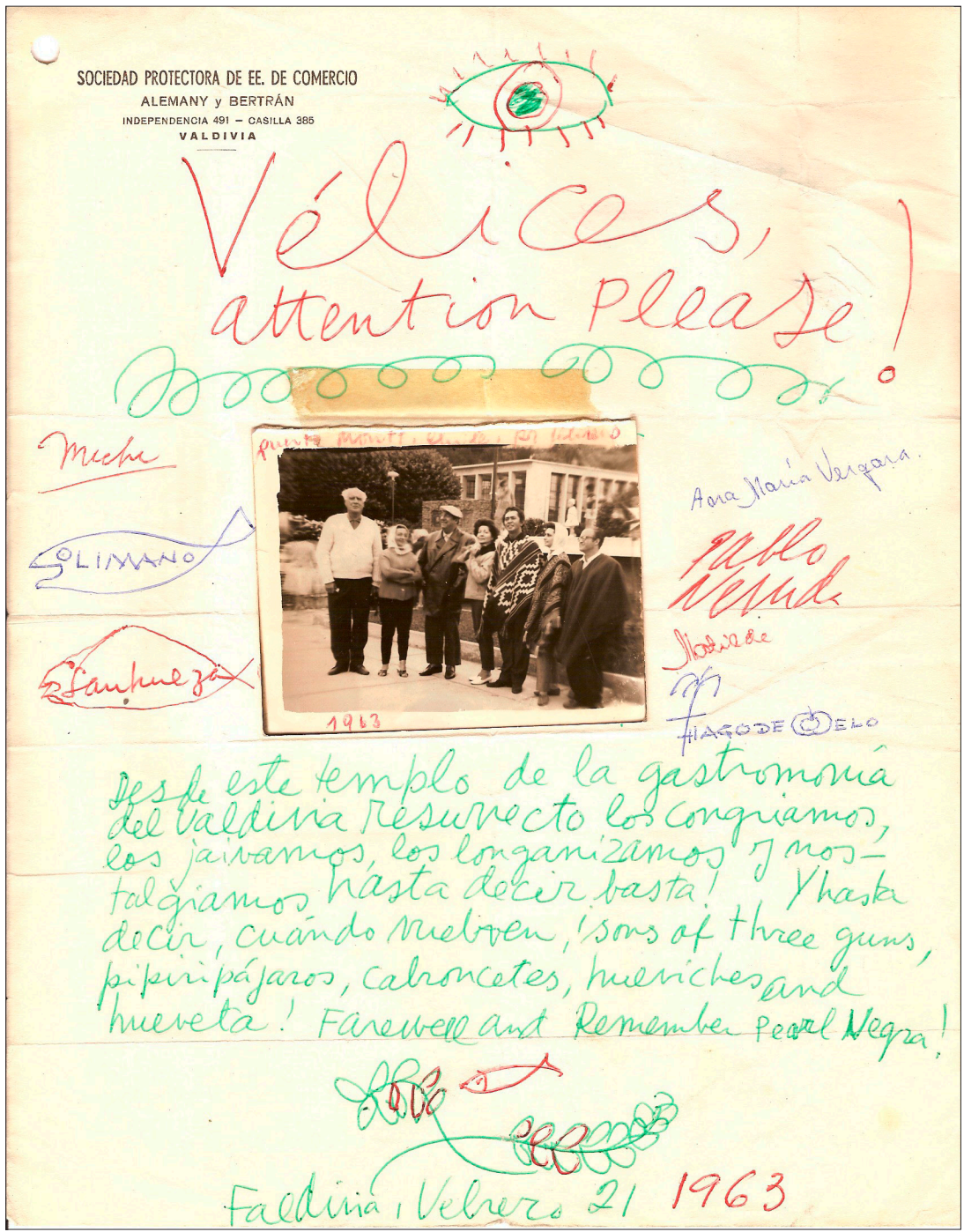

Carta de 21 de febrero de 1963: incluida en Quezada, Abraham (2011), Pablo NerudaClaudio Véliz, Correspondencia en el camino al Premio Nobel, 1963-1970. Santiago: Ediciones de la Dirección de Bibliotecas, Archivos y Museos, página 43. 
Una particularidad de esta epistolografía se expresa también en el color y tipo del papel y la tinta verde utilizada en la gran mayoría de las veces. Invariablemente sus escritos los realizaba en papeles de colores de tonos celestes, blanco invierno, amarillos y anaranjados. Siempre de fina textura y con la presencia permanente de epígrafes y de su simbología (el pez en medio de la esfera armilar). Y dependiendo de su estado de ánimo, acostumbraba a incluir el "recurso a las imágenes", a través de dibujos y croquis, los que junto con instalar la nota festiva o circunstancial, pareciera que venían a completar un espacio comunicacional de marcados anhelos rememorativos donde la intención afectiva se mezcla con imágenes que evocan lugares o momentos de alegría y tristeza, conformando un todo coherente de original factura. Al confrontar y revisar sus envíos, se constata que el desenfado y atracción que provoca el talante y catadura del poeta no logran influenciar decisivamente a sus corresponsales. No obstante, el retrato que se logra de él es inmediato, a la vez que se da cuenta del ambiente social, cultural y literario de entonces. En suma, una epistolaridad auténticamente nerudiana, sin academicismo ni estructuras estilísticas, exudando intención comunicativa, resolución y claridad, acompañada de coherencia y afecto sencillo y profundo hacia sus amigos y cercanos, y de dureza y acritud hacia sus antagonistas circunstanciales.

\section{COLOFÓN}

La intensa actividad político-social, así como la concepción de la amistad en Pablo Neruda requería de un espacio emocional amplio, lo que se reflejó en su poesía, pero también en sus escritos privados. Por ello, la exhumación de estos ricos materiales es una acción válida, ya que a partir del testimonio confesional y revelador de su intimidad se contribuye de modo significativo a configurar el panorama de su existencia. Se podrá discrepar acerca de la forma en que vuelca el tesoro de su intimidad o el decir que las epístolas tienen mayor o menor interés, pero en su conjunto, son un aporte insoslayable a lo planteado. El género epistolar debe ser admitido entonces como parte de "la otra escritura" del poeta, que no se propuso serlo, pero que por dar cuenta de aspectos privados e íntimos, por la propia mano del protagonista, es valiosa. En su "literatura intima", Neruda ha escrito su vida y pintado su retrato con profundidad, sinceridad y belleza. Pocos escritores han dado más de sí mismos en sus cartas. Neruda está allí casi enteramente como es. De este modo se completan y/o explican momentos de su vida. Al mismo tiempo, las cartas resultan apropiadas para conocer y entender los entresijos y circunstancias de su portentosa obra. En su epistolario, en definitiva, está probablemente su mejor biografía. 


\section{BIBLIOGRAFÍA}

Aguirre, Margarita, comp. Pablo Neruda, Héctor Eandi: correspondencia durante Residencia en la tierra. Buenos Aires: Editorial Sudamericana, 1980.

Loyola, Hernán. Pablo Neruda Obras completas, V vols., Barcelona: Galaxia Gutenberg Círculo de Lectores, 2002.

Montes, Hugo, comp. Cartas a Laura. Madrid: Ediciones Cultura Hispánica del Centro Iberoamericano de Cooperación, 1978.

Neruda, Pablo. Para nacer he nacido. Barcelona: Seix Barral, 1978. Confieso que he vivido, Barcelona: Seix Barral, 1985.

Olivares, Edmundo. Pablo Neruda: Los caminos de América. Santiago: Lom Ediciones, 2004. Quezada, Abraham, comp. Pablo Neruda, epistolario viajero, 1927-1973. Santiago: Ril Editores, 2004. comp. Correspondencia entre Pablo Neruda y Jorge Edwards, 1962-1973. Santiago: Alfaguara, 2007. comp. Cartas a Gabriela. Santiago: Ril Editores, 2009. comp. Pablo Neruda - Claudio Véliz, Correspondencia en el camino al Premio Nobel, 1963 -1970. Santiago: Centro de Investigaciones Diego Barros Arana, 2011. 2014. Pablo Neruda Salvador Allende, una amistad, una historia. Santiago: Ril Editores,

Reyes, Bernardo. Neruda, retrato de familia 1904-1920. Santiago: Dolmen Ediciones, 1997. "Neruda + Neruda". Estudios Públicos No 94 (otoño). Santiago: Centro de Estudios Públicos, 2004.

Teitelboim, Volodia (). Neruda, la biografía. Albacete: Ediciones Merán, 2003.

Vial, Sara. Neruda vuelve a Valparaíso. Valparaíso: Ediciones Universitarias de Valparaíso, 2004.

Woodbridge, Hensley y David Zubatsky. Pablo Neruda: An Annotated bibliography of biographical and critical studies. New York: Gardland Publishing, Inc. Publisher, 1988. 